\title{
Editorials
}

\section{Advance care planning in general practice:}

\author{
promoting patient autonomy and shared decision making
}

\section{WHAT IS ADVANCE CARE PLANNING AND WHY IS IT IMPORTANT?}

Advance care planning is a process of formal decision making to help patients establish decisions about their future care which takes effect when they lose capacity to make decisions for themselves. " It is a voluntary process and a written record of patients' wishes that can be referred to by carers and health professionals in the future. Previous terms and concepts used in the UK include 'living wills' and 'advance directives'. Advance care planning is important in identifying early palliative care needs and recognising the end of life. $^{2}$ Other benefits include less aggressive medical care and an improved quality of life near death. It also helps families prepare for the death of a loved one, resolve family conflict, and cope with bereavement. ${ }^{3}$

\section{ADVANCE STATEMENTS, ADVANCE DECISIONS TO REFUSE TREATMENT, AND LASTING POWER OF ATTORNEY}

Advance statements (sometimes known as statements of preferences) can be about either medical treatment or social aspects of care and are not legally binding, but have to be taken into account when decisions are made about the patient after they lose capacity. They can be either verbal or written. ${ }^{4}$

Advance decisions to refuse treatment are legally binding documents which allow patients to refuse specific treatment if they lose capacity. Patients can refuse medical and nursing treatment in advance but not basic care such as the offer of food and drink by mouth. Verbal wishes to refuse treatments which do not sustain life can also be recorded in the patients' case notes (or records). An advance decision to refuse treatment only comes into effect once the patient loses the capacity to make that particular decision. The only circumstance where it would not be binding is if a patient is detained under the Mental Health Act when they can be treated for their mental health disorder without their consent (electroconvulsive therapy is an exception to this rule). In England and Wales the code of practice of the Mental Capacity Act ${ }^{5}$ sets out principles designed to protect patients with impaired capacity and their carers, who have to make decisions regarding their care and treatment. GPs have a legal duty to abide by a patient's wishes regarding

"Advance care planning is important in identifying early palliative care needs and recognising the end of life.

a health-related advance decision which comes into effect when they have lost the capacity to make that particular decision. In Scotland, the Adults with Incapacity Act requires decisions about medical treatment to be directed by the patient's best interest, but it does not include the right to refuse treatment, however a valid and applicable advance decision would probably be respected, if challenged in court. ${ }^{6}$

Lasting power of attorney allows patients to nominate someone to whom they want to give decision-making powers if they lose capacity. There are two types of decision: 'property and financial affairs' and 'health and welfare'. More than one person can be nominated or different people can be nominated for different decisions. If there are concerns that someone is making decisions not in the patient's best interest, the decision can be challenged in the Court of Protection which may appoint a court deputy, usually someone close to the patient, who can take best interest decisions on the patient's behalf

\section{HOW SHOULD GPS APPROACH ADVANCE CARE PLANNING?}

\section{Assessing mental capacity}

There are two components to consider when assessing a patient's mental capacity

- A diagnostic component. This is positive when the patient has an impairment of, or disturbance in, the functioning of the mind or brain

- A functional component. This applies only if the diagnostic component is positive. Patients have lost mental capacity when they lose one or more of the following elements: being able to understand; being able to retain, use and weigh information; or being able to communicate their decisions.

GPs should be aware that loss of mental capacity is decision specific and not global and can fluctuate over time. For example, patients may be temporarily incapacitated by delirium which is not uncommon in patients with palliative care needs, by an episode of sepsis, or through the use of alcohol and they may need to be reviewed frequently. ${ }^{3}$

\section{Initiating an advance care planning discussion}

Advance care planning discussions usually take place with a trusted and familiar GP who can elicit a patient's care preferences as they approach the end of life. Possible triggers for an advance care planning discussion could include the first appointment following hospital discharge or on the admission to a care home. At that point it may be useful to link it with an early palliative care approach. Some patients will need time to think and reflect, and therefore, the initial planning process may extend over a number of consultations. In any event the focus should be on communication rather than specific interventions or outcomes and a 'tick box' approach should be avoided.

\section{Asking three simple questions}

The Gold Standards Framework ${ }^{7}$ suggests asking patients approaching the end of life three simple questions:

- What do you want to happen? ladvance statement of wishes and preferences)

- What do you not want to happen? ladvance decision to refuse treatment and do not attempt resuscitation orders) 
- Who will speak for you? (lasting power of attorney).

\section{Reviewing advance care planning decisions}

Several factors should prompt a review of advance care planning decisions:

- a change in the patient's place of residence;

- a change in the patient's perception of their quality of life;

- new therapeutic options; and

- a change in the patient's values or aims as the condition progresses.

By regularly reviewing advance care planning decisions while the patient still has the mental capacity to do so, the document can reflect their current wishes and increase the likelihood that it will be judged as valid and applicable at the relevant time. ${ }^{3}$

\section{HOW COMMON ARE ADVANCE CARE PLANS?}

In 2014 an audit of end of life care by the Royal College of Physicians found that only $4 \%$ of 9000 patients admitted to hospital had made some form of advance care plan before their admission. ${ }^{8}$ In a more recent general practice study $58 \%$ of patients who had died with a chronic condition had an advance care plan; $74 \%$ with cancer and $41 \%$ with organ failure. The authors attributed the lower organ failure figure to the professional, patient, and societal challenges which were involved in identifying patients for palliative care who had a non-cancer diagnosis. ${ }^{?}$

\section{ELECTRONIC PATIENT RECORDS}

In some areas of the UK, information regarding patients' advance care planning decisions are held on electronic patient records which are made available to a range of relevant professionals. This has been shown to lead to an increase in the number of patients dying in their preferred place of death ${ }^{10}$ but as yet there is no trial data available to prove a causal link. It may be that patients with advance care plans would be more likely to die

\section{ADDRESS FOR CORRESPONDENCE}

\section{Ian J Hamilton}

Institute of Health and Wellbeing, University of Glasgow, 1 Lilybank Gardens, Glasgow G12 8RZ UK.

\section{E-mail: ijdhamiltondadoctors.org.uk}

in their preferred place of death lusually their own homel anyway. More recently the focus has been on electronic palliative care coordination systems such as key information summaries (KIS) in Scotland ${ }^{11}$ and Co-ordinate my Care (CMC) in England ${ }^{10}$ which facilitate the sharing of key patient information across care settings, however there have been concerns expressed regarding the implementation, sustainability, cost-effectiveness, equality, and service capacity of these systems. ${ }^{12}$

\section{CONCLUSION}

The aim of advance care planning is to achieve 'a good death' but patients may not wish to engage in discussions about future care as it involves them in thinking about a deterioration in their condition and GPs might be unwilling to initiate advance care planning discussions as they may feel that discussing prognosis with patients will cause them undue distress and destroy hope. ${ }^{4}$ Other reasons preventing GPs from initiating advance care planning discussions include prognostic uncertainty, limited collaboration with secondary care, and a resistance to any kind of 'tick box' approach. Advance care planning does have the potential to promote patient autonomy and shared decision making ${ }^{13}$ and to improve quality of care at the end of life, leading to less in-hospital death and increase in hospice use. ${ }^{14}$ However, without a significant change in patients' perception and GPs' attitudes it is unlikely to become more widely adopted.

\section{Ian J Hamilton,}

Researcher, Institute of Health and Wellbeing, University of Glasgow, Glasgow.

\section{Provenance}

Freely submitted; externally peer reviewed.

DOI: https://doi.org/10.3399/bjgp17X689461

\section{REFERENCES}

1. Hayhoe B, Howe, A. Advance care planning under the Mental Capacity Act 2005 in primary care. Br J Gen Pract 2011; DOI: https://doi. org/10.3399/bjgp14X683029.

2. Mitchell S, Loew J, Millington-Sanders C, et al. Providing end-of-life care in general practice: findings of a national GP questionnaire survey. Br J Gen Pract 2016; DOI: https://doi. org/10.3399/bjgp16X686113

3. Mullick A, Martin J, Sullnow L. An introduction to advance care planning in practice. BMJ 2013; 347: $f 6064$.

4. Barnes $K$, Jones L, Tookman A, et al. Acceptability of an advance care planning schedule: a focus group study. Palliat Med 2007; 21(1): 23-28.

5. Department for Constitutional Affairs. Mental Capacity Act Code of practice 2007. https:// unw.gov.uk/government/uploads/system/ uploads/attachment_data/file/497253/Mentalcapacity-act-code-of-practice.pdf laccessed 6 Feb 2016).

6. Dollman G. Medical ethics: The right to choose. MDDUS/Summons (autumn) 2016. http://mww.mddus.com/resources/ resource-type/publications/summons/2016/ autumn-2016/the-right-to-choose/ laccessed 7 Feb 2017).

7. The Gold Standards Framework. Advance care planning discussions. http://wnw. goldstandardsframework.org.uk/advancecare-planning laccessed 6 Feb 2016).

8. Royal College of Physicians. End of life care audit - dying in hospital. 2016. https://wnw. rcplondon.ac.uk/file/3334/download?token=0SZLsyq (accessed 7 Feb 2016).

9. Tapsfield J, Hall C, Lunan C, et al. Many people in Scotland now benefit from anticipatory care before they die: an after death analysis and interviews with general practitioners. BMJ Support Palliat Care 2016; pii: bmjspcare-2015-001014.

10. Smith CF, Riley J. Coordinate My Care. A clinical service for end-of-life care underpinned by an IT solution. http://www.bmj. com/rapid-response/2011/11/03/coordinatemy-care-clinical-service-end-life-careunderpinned-it-solution laccessed 6 Feb 2016).

11. Finucane A, Tapsfield J, Hall C. Electronic key information summaries can highlight patients wishes out of hours. BMJ Support Palliat Care 2016; 6: 405-406.

12. Petrova M, Riley J, Abel J, et al. Crash course in EPaCCS (Electronic Palliative Care Coordination Systems): 8 years of successes and failures in patient data sharing to learn from. BMJ Support Palliat Care 2016; doi: 10.1136/bmjspcare-2015-001059.

13. Boyd K, Mason B, Kendall M, et al. Advance care planning for cancer patients in primary care: a feasibility study. Br J Gen Pract 2010; DOI: https://doi.org/10.3399/bjgp10X544032.

14. Bischoff K.E, Sudore R, Miao Y, et al. Advance care planning and the quality of end-of-life care in older adults. J Am Geriatr Soc 2013; 61(2): 209-214; doi: 10.1111/jgs.12105. 